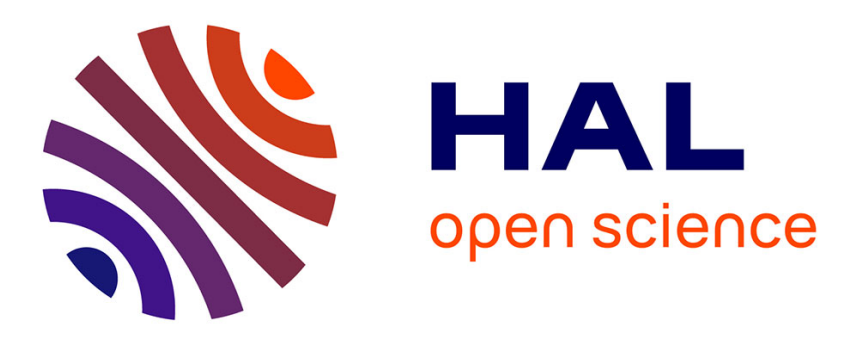

\title{
Selection of Free Software Useful in Business Intelligence. Teaching Methodology Perspective
}

Mieczyslaw Owoc, Maciej Pondel

\section{To cite this version:}

Mieczyslaw Owoc, Maciej Pondel. Selection of Free Software Useful in Business Intelligence. Teaching Methodology Perspective. 4th IFIP International Workshop on Artificial Intelligence for Knowledge Management (AI4KM), Jul 2016, New York, NY, United States. pp.93-105, 10.1007/978-3-319-929286_6. hal-01950014

\author{
HAL Id: hal-01950014 \\ https://hal.inria.fr/hal-01950014
}

Submitted on 10 Dec 2018

HAL is a multi-disciplinary open access archive for the deposit and dissemination of scientific research documents, whether they are published or not. The documents may come from teaching and research institutions in France or abroad, or from public or private research centers.
L'archive ouverte pluridisciplinaire HAL, est destinée au dépôt et à la diffusion de documents scientifiques de niveau recherche, publiés ou non, émanant des établissements d'enseignement et de recherche français ou étrangers, des laboratoires publics ou privés. 


\title{
Selection of Free Software Useful in Business Intelligence. Teaching Methodology Perspective
}

\author{
Mieczysław Owoc and Maciej Pondel \\ Wroclaw University of Economics, Poland \\ \{mieczyslaw. owoc, maciej.pondel\} @ue.wroc.pl
}

\begin{abstract}
Modern decision-taking processes are supported by advanced information technologies. There are many products on the market representing more and more smart solutions therefore selection of proper software is not easy especially if managers are oriented on minimizing costs in computer infrastructure. It is significantly important for people representing small and medium-sized enterprises. On the other hand it is common expectation of well-educated staff as graduates of academia. This is very essential assumption for educational sector where teaching methodology and defined software packages are discussed and proposed. Initial point of the research is discussion of teaching methodology essence and diversification. In our paper we propose methodology of selection free software tools essential in education limited to teaching of business intelligence. Especially Magic Quadrant prepared by Gartner is carefully analyzed. The main software products offering by different companies were taken into account and procedure of selection was defined including list of criteria essential in the choice of a product. The list of criteria embraces different perspectives of the selection. Power BI as the selected tool is presented in more details.
\end{abstract}

Keywords: Business Intelligence teaching, free software, methodology of teaching, supporting of decision-making

\section{Introduction}

B usiness Intelligence (BI) approach and technology seems to be inherent part of current business sector. That is why it is an essential part of teaching program on the Business Informatics field of study and other relate. Main goals of learning Business Intelligence (considered in the 
completed project in the Erasmus+ framework DIMBI: Developing the innovative methodology of teaching Business Informatics) are:

- understand the objectives of Business Intelligence systems implementation,

- understand the process of knowledge acquisition from data,

- gather skills necessary to collect project stakeholders requirements in terms of BI implementation,

- understand the most important features and capabilities of BI tools,

- be able to map the requirements to the capabilities of BI tools,

- $\quad$ gather skills essential to solve most common problems and issues concerning implementation of Business Intelligence,

- $\quad$ practise implementation of Business Intelligence solution in defined business perspectives and selected IT tools.

Authors assume that detailed recognition of one selected IT tool should not be considered as the objective of BI course. If a student understands the overall process and is familiar with a specific tool he or she is able to utilise those skills quickly learning other systems that he or she meets in practise. Of course it would be beneficial if a student uses the same tool in a real projects that he or she learns during studies but we do not intend to teach students all possible IT tools that are available on the market. During the research on various BI systems we found that the essential aspects of all systems are relatively similar in terms of their functionality and ways of usage and it is quite simple to transfer student's experience from one tool to another.

The process of IT tools selection should start from definition of criteria that fully support assumed objectives. The most important criterion is existence of free edition of the tool. Authors of the paper find it crucial that system is available for free. Even most advanced and advantageous system can be considered useless in learning process if it is not easy accessible. The aim of our research project is to deliver the course that is available in a regular form of classroom training and also as an online course. The course will be available for every willing university or students.

The licence limits can discourage potential students from using the tool and from attending the whole prepared course. That is why the availability of a free version was in our case the must. Authors understand that IT tools can be delivered in a various models and free version in each case can have a different meaning. Existence of a free version can signify that (see [Laurent, 2004]):

- Tool is available in an open source model (GNU GPL, LGPL or Mozilla Licence)

- Tool is available under MIT, BSD, Apache or Academic Licence 
- Tool is available as commercial one but it has free edition that contains defined limitations.

Regarding limitations - providers of those tools can define them on a different levels. Some limit available features of software other limit the amount of data that can be processed on a free tool. From authors' perspective limitation of system's feature is of course a meaningful disadvantage. Limitations on other levels like data capacity or others restricting availability of the tool usage in enterprise environment (eg. integration with corporate $\mathrm{AD}$, number of concurrent data sources) may be considered less important and be acceptable for learning purposes.

\section{Teaching Methodology of Business Intelligence}

Modern higher education faces with many problems and challenges. Basically, it is result of continuous civilizational progress and growing up student's requirements.

There are many opinions presenting challenges in this matter, for example P. Raj keeps the following: education for all, education cost and education leveraging jobs [Quora 21]. Therefore society, economics and marketing aspects are considered. On the other side higher education in globalization world according to S.L. Robertson should shaped competitive abilities of students (see: [Robertson 2010]).

All the mentioned factors have the real impact on teaching methodology independently of topics learned. Teaching methodology as the defined set of methods "comprises the principles and methods used by teachers to enable student learning" ([Wikipedia/teaching_methods]) is strictly connected with techniques and tools useful in development of student competencies and abilities.

It is very important especially in the courses where the usage of software tools is the must. Business intelligence is an example of such discipline. lows:

Main objectives of teaching business intelligence can be defined as fol-

- understanding the objectives of Business Intelligence systems implementation,

- $\quad$ understanding the operation of knowledge acquisition from data warehouse models,

- gathering skills necessary to collect project stakeholder requirements in terms of BI implementation,

- $\quad$ understanding the most important characteristics and capabilities of BI tools,

- being able to map the requirements to the capabilities of BI tools, 
- $\quad$ gathering skills essential to solve most common troubles and matters concerning implementation of Business Intelligence,

- practical implementation of Business Intelligence solutions in selected business perspectives and selected IT tools.

All of the mentioned objectives should be considered in Business Intelligence phases context. Assuming BI process as a composition of crucial phases: define, integrate, analyze and visualize BI - teaching methods and supporting tools should embrace one or more phases. General idea of the process is presented in the Fig. 1.

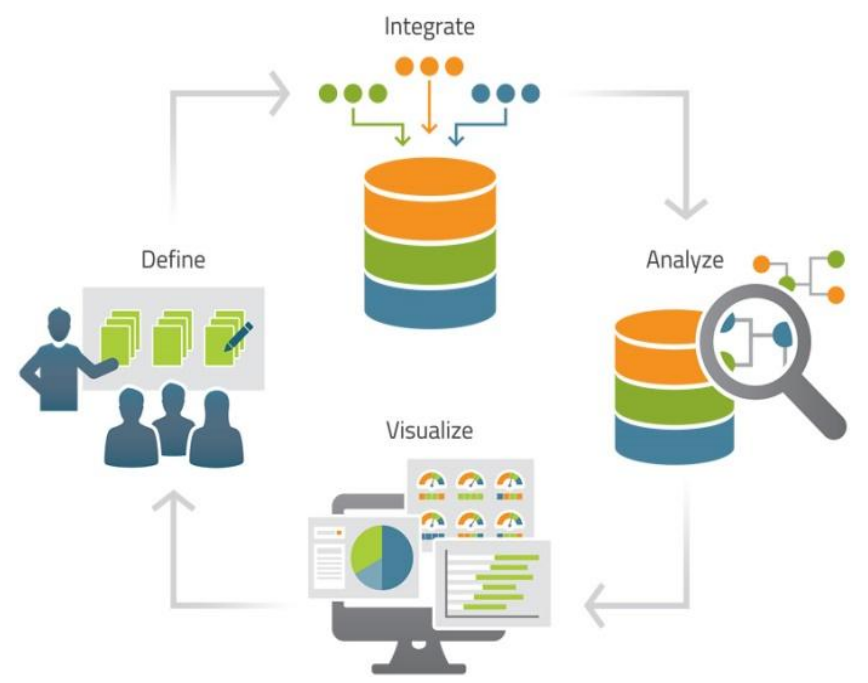

Fig.1. Phases of BI process

Source: http://www.tacticaledge.us/services/softwaredevelopment/analytics-and-business-intelligence/

The nature of the phases introduced into BI forces the use of computer tools throughout the cycle. It is critical for integration of data sources, analysis of big data and visualization results in many forms.

Teaching methodology applied for obtaining BI educational objectives can be formulated as a set of traditional and innovative methods of delivering knowledge and developing student competences. There is a big number of formulated teaching methods prepared in more general applying or oriented on particular domains (see: [Haroun 2017] classified as teacher- or student-centered, direct instructions and many others. Postulated and checked for BI methods are depicted in Fig. 2. 
The list of suggested methods is a bit disputable but expresses the most frequently applied solutions starting from traditional lectures up to more creative ways of training student capabilities like performing projects or solving problems with BI tools. Some of them (marked with " $\sqrt{ }$ " symbol) require advanced software tools. It is especially important in case of BYOD ("bring your own device") formula - where students are obliged to use their personalized technologies during education. Similarly "Solving problems using BI tools" method requires from students the usage of adequate software tools in order to integrate data sources, analyze them and visualize results helpful in the defined quests.

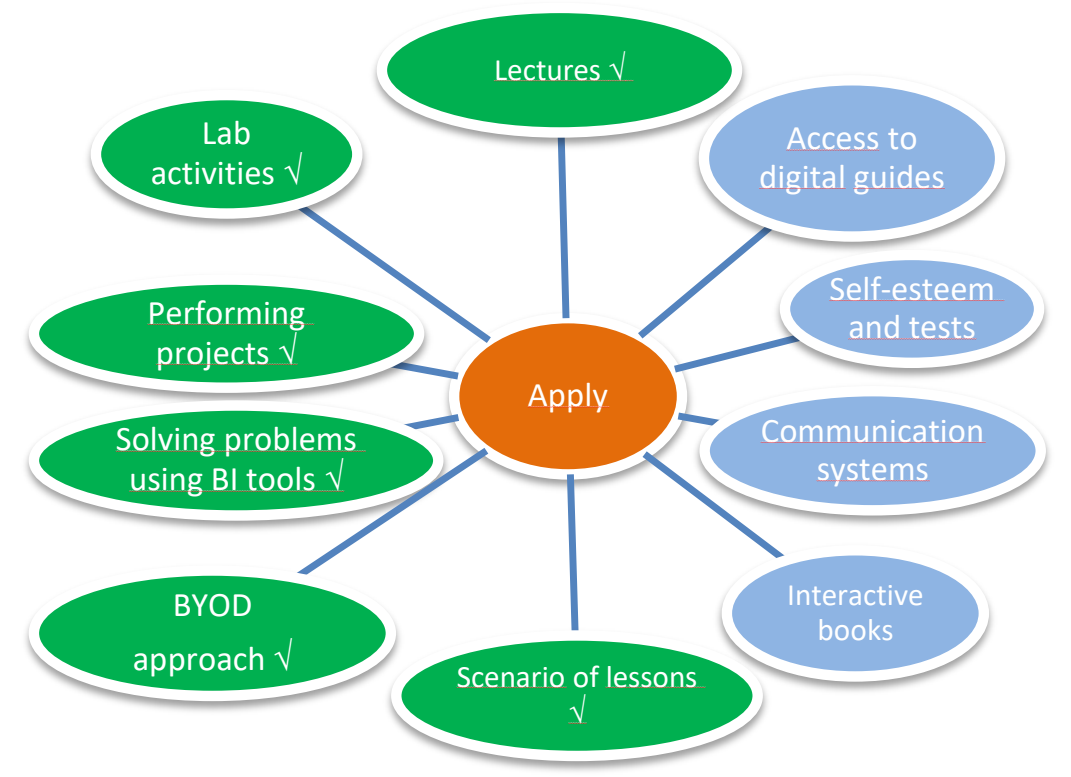

Fig.2. Methods assumed in teaching of BI

Source: own elaboration

The tools accompanying teaching methodology can support more than one phase (for example analysis and visualization) and be strictly connected with the defined methodology. The main problem in selection of the tool is fulfill potential users requirements. 


\section{Related Works and the Selection Method}

The problem of selection right tools that can be applied for particular users is very old and still very actual, especially when market of these products is very rich. Therefore managers looking for appropriate software should take into account many aspects including functionality, easiness of the usage, supporting and cost of software acquisition and maintenance. There are several approaches and guidelines that can be useful in the selection of software tools. Below is a list of examples offering relatively objective approach to select the discussed software:

- Survey on evaluation and selection the right BI tool [Sherman 2015] where

- Survey on selection BI tools [BITSu 2016] where independent group of professionals depicted about 200 criteria aggregated in 12 aspects allowing for selections the best solution for an user,

- Selection of BI tools [BITSe 2016] where comparison of selected platforms is discussed eg. Business Objects against Oracle Hyperion or IBM Cognos,

- Presentation of BI products [BISP 2016] where characteristics of business intelligence software is delivered from quality communication and resources points of view,

- Best practices for BI tools selection [BP4BI 2006] where Authors describe very useful approach covering the whole selection process starting from the selection of business champion up to make an Informed Business decision focused on financial aspect of this decision,

- Team expert is preparing solution for customers [BI Verdict 2016], including analyst and customer opinions in the context of balanced perspective on BI tools market

One of the most prestigious companies presenting surveys on different IT products is Gartner group - the report on BI tools covers five different cases and essential capabilities of the discussed software [GartnerBI 2017].

Main use cases refer to the following aspects:

- Agile Centralized BI Provisioning - stressing the self-contained data management capabilities of the particular platform e.g. an agile IT-enabled workflow, 
- Decentralized Analytics - essential when it is capability of a creation workflow from data to self-service analytics,

- Governed Data Discovery - denotes IT-managed content including at least: governance, reusability and promotability,

- Embedded BI - a workflow embraces embedded BI content,

- Extranet Deployment - including analytical content availability for external customers.

The presented cases exhaust main possible options of usability BI tools limited to modern technological workflows.

Capabilities of the analyzed BI tools can be evaluated using several criteria. Criteria set has been defined in the following groups:

- Infrastructure - covering four criteria; BI platform administration, Cloud BI option, security and user administration and connectivity to structured as well as unstructured data sources.

- Data Management - taking into account different activities important from administration point of view expressed as three criteria: governance and metadata management, self-contained ETL and data storage processes,

- Analysis and Content Creation - a list of key (from analytical point of view) four criteria including: embedded advanced analytics, analytic dashboards, interactive visual exploration and mobile exploration and authoring,

- Sharing of Findings - referring to three output criteria: embedded analytic content, publishing analytic content and collaboration and social $\mathrm{BI}$, essentially improving presentation of the analytical results.

The presented fourteen criteria apart of the mentioned five cases were used to demonstrate capabilities of important on BI market products traditionally visualized as four quadrants representing niche players, visionaries, challengers and leaders (see Figure 3).

In the Figure all sorts of producers are present commercial as well as so-called free- software. Actually just three platforms are located in the quadrants Leaders - Tableau, Qlik and Microsoft; there are some versions of the products available as free of charge packages. Microsoft Power BI is representative of software that cover all necessary functionalities as BI and Analytics platform. Note also, that some packages offers capabilities essential in the ETL process - so they may work as Data Warehouse software (for example SAS, SAP and Pentaho products). 


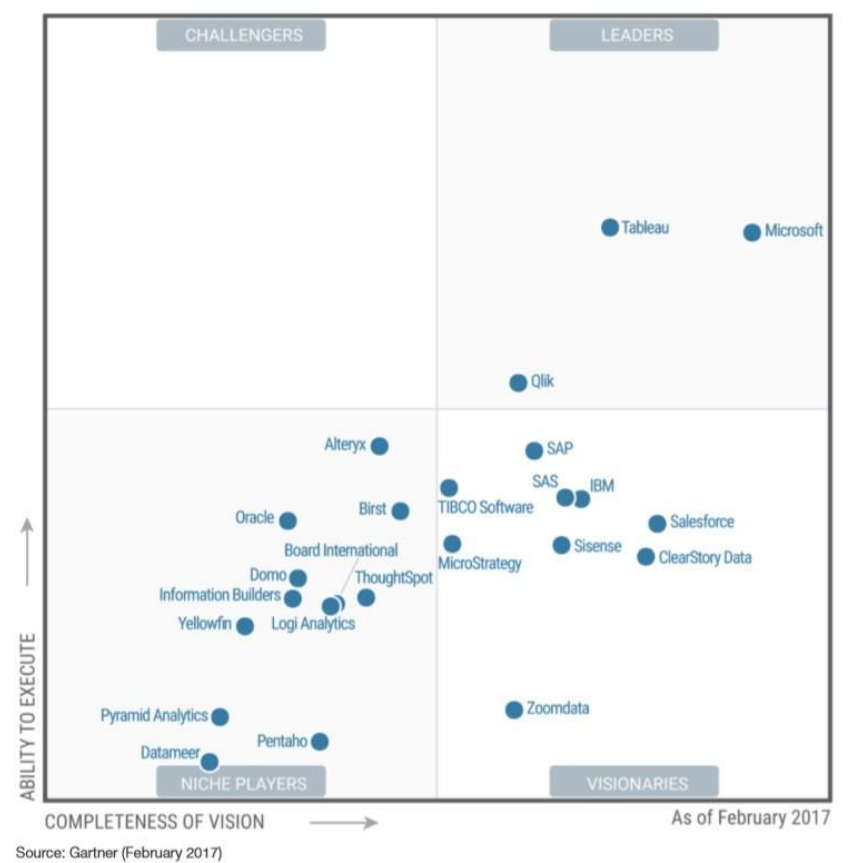

Figure 3. Magic Quadrant for Business Intelligence and Analytics Platforms

Source: [GartnerBI 2017].

J. Underwood in his research explores 2017 Gartner BI Magic Quadrant Results stressing changing roles of some producers and monitoring tendency of leader's proposal [Underwood 2017].

Interesting characteristics of tools limited to open-source category is presented by Lindsay Wise (see [Wise 2012]). In this essay these platforms are termed as Open-Source Business Intelligence (OSBI) and contain four crucial components: Data Warehouse, Data Integration, Analytics Engine, and Reporting combined with Dashboard functionality. According to OS and BI solutions particular platforms should fulfil business as well as technological requirements; convergence approach in supporting such project is a must.

Keeping in mind all the mentioned approaches we have to focus on teaching Business Intelligence aspects in the selection of appropriate platforms. Two dimensions in the elaborated method must be defined: list 
of free of charge BI Analytic Tools and criteria of evaluation the particular platforms. So, we've defined free of charge platforms as the subcategory of discussed earlier non-commercial and open-source platforms.

Our research was limited to the following platforms:

- SAP Lumira ( http://saplumira.com/)

- Qlik Sense (http://www.qlik.com/products/qlik-sense)

- Tableau (http: www.tableau.com/)

- MS Power BI (https://powerbi.microsoft.com/en-us/)

- Pentaho (http: www.pentaho.com/)

- JasperSoft BI (http: www.jaspersoft.com/)

We've tested the itemized platforms through performing BI projects by students in the Data Warehouse (DW) and Business Intelligence courses or as topics of their Bachelor or Master Thesis.

The second dimension - the criteria set - represents selected capabilities essential from educational point of view. Taking into account earlier presented we've focused on the following aspects: general look, intuitiveness, easiness of implementation, safety, support, BI analysis, data sources, other functionality, and two educational perspectives: DW and BI.

\section{Results of comparative analysis}

The presented in the previous section selection method has been applied to evaluate of usability the included tools in teaching Business Intelligence topics. Teams of students familiar with particular platforms prepared reports on fulfil software capabilities using defined criteria. They voted independently under supervision of tutors. In some cases they needed additional explanation about particular criteria. For example general look was mostly identified with the interface offered by producers. At least two teams were appointed to grade one platforms. We used scale 0 (the worst) to 5 (the best) grades for evaluation purpose. Most of the criterion defined acquired qualitative measures (general look, easiness of implementation) while the others quantitative (additional functionality or licence). Comparative analysis of the evaluated platforms is presented in Table 1. Apart of the defined earlier criteria two additional capabilities were included: educational aspects separately for teaching Business Intelligence and Data Warehouse.

The highest ranked was MS Power BI as the platform with 6 best scores (especially important considering BI educational aspect. Lower 
position of this platform in DW educational point of view can be compensated through the usage of the second platform. In our opinion combination of two tools: MS Power BI and Pentaho looks very promising.

Table 1. Evaluation of BI Analysis Tools

\begin{tabular}{|c|c|c|c|c|c|c|}
\hline \multicolumn{7}{|c|}{ BI Analysis Tools Free of charge } \\
\hline Criterion & $\begin{array}{c}\text { SAP } \\
\text { Lumira }\end{array}$ & $\begin{array}{r}\text { Qlik } \\
\text { Sense }\end{array}$ & Tableau & $\begin{array}{c}\text { MS } \\
\text { Power BI }\end{array}$ & Pentaho & $\begin{array}{c}\text { Jaspersoft } \\
\text { BI }\end{array}$ \\
\hline Look & 4 & 4 & 4 & 5 & 3 & 4 \\
\hline Intuitiveness & 4 & 4 & 5 & 4 & 3 & 3 \\
\hline $\begin{array}{l}\text { Easiness of } \\
\text { implementation }\end{array}$ & 3 & 4 & 4 & 4 & 2 & 3 \\
\hline Safety & 2 & 5 & 3 & 5 & 3 & 2 \\
\hline Support & 2 & 4 & 4 & 4 & 0 & 3 \\
\hline BI Analysis & 5 & 5 & 3 & 5 & 4 & 3 \\
\hline Data Sources & 1 & 4 & 3 & 5 & 5 & 4 \\
\hline $\begin{array}{l}\text { Additional } \\
\qquad \text { Functionality }\end{array}$ & 4 & 3 & 3 & 5 & 5 & 3 \\
\hline Licence & 2 & 5 & 3 & 4 & 5 & 2 \\
\hline $\begin{array}{c}\text { Educational aspect } \\
(D W)\end{array}$ & 3 & 4 & 3 & 3 & 5 & 5 \\
\hline $\begin{array}{l}\text { Educational aspect } \\
\text { (BI) }\end{array}$ & 4 & 4 & 3 & 5 & 4 & 3 \\
\hline Summary & 34 & 46 & 38 & 49 & 39 & 35 \\
\hline
\end{tabular}

In the next Figures (4 and 5) the platforms are presented stressing educational capabilities (for BI and DW respectively) in the context of summary evaluation. 


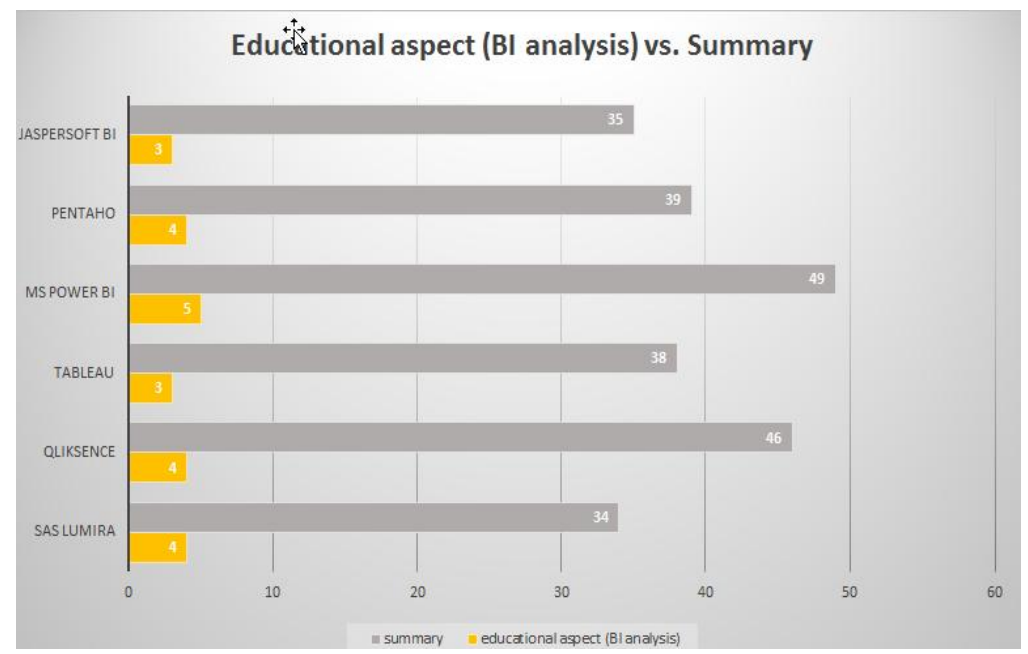

Figure 4. Educational aspect of BI analysis vs. Summary Source: own elaboration

The best position belongs to MS Power BI, which was elected as a leader for BI education. Additional characteristics of this tool is presented in the next section.

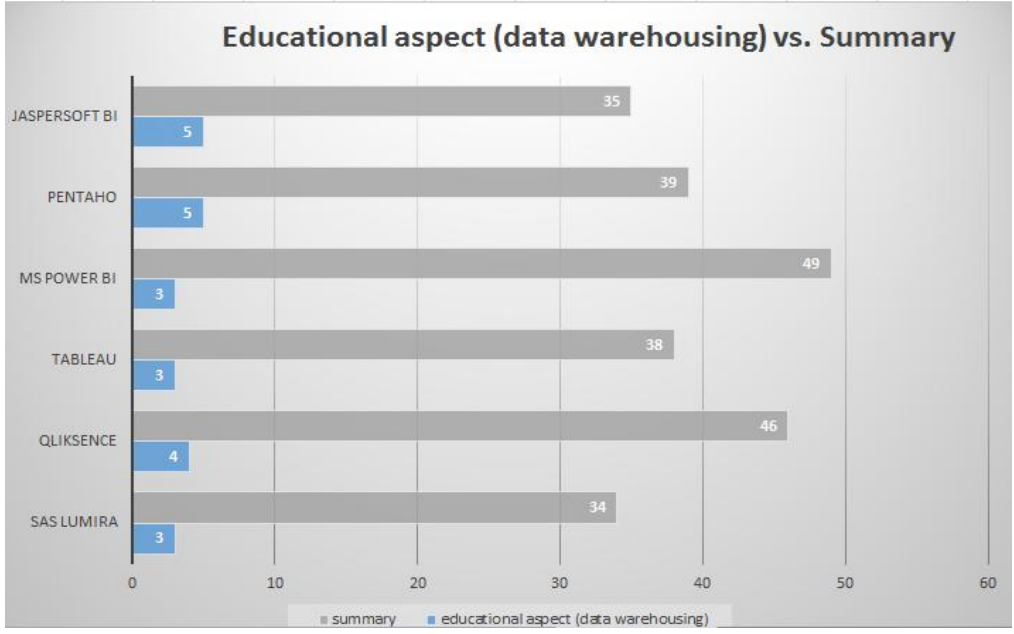

Figure 5. Educational aspect of DW vs. Summary Source: own elaboration. 
The best position of the second elected platform Pentaho is confirmed on this Figure.

\section{Main Properties of Power BI}

Power BI is a Microsoft developed suite that belong to the group of tools called Self Service BI. Of course the main goal of such tool is to provide Business Intelligence capability but the difference expressed in Self-service boils down to the fact that in this tool the final user (accountant, analyst, manager and many other) is capable to build their own analysis (data models, reports, dashboards) without relying on the help from IT department (see [Web 2014]).

Also, it is important to emphasize that there are two kinds of self-serve BI user (see [Pondel 2015]):

- Analytics Power Users who create visual apps from multiple data sources - both internal and external.

- Regular Users that can fully explore the visual apps created by power users or IT.

Power BI is a cloud-based business analytics service that provides user with the most important BI features like creating rich interactive reports with Power BI Desktop and monitoring the health of business using live dashboards. It includes 2 main approaches to analyse data:

- Power BI Desktop,

- $\quad$ Power BI for Office 365.

Power BI desktop is a free desktop tool in which you can (see [PowerBI Desktop 2016]):

- Import. You can import data from a wide variety of data sources. After user connects to a data source, he or she can shape the data before importing to match analysis and reporting needs.

- Model data. Power BI Desktop provides data modelling features like autodetect and manual relationships definition, custom measures, calculated columns, data categorization, and sort by column. There is Relationship View, where user gets a customizable diagram view of all tables and the relationships between them.

- Create reports. Power BI Desktop includes Report View. There user can select the fields he wants to display, add filters and choose visual. Prepared visualisations are interactive and authors consider them very impressive.

- Save. Power BI Desktop, allows user to save work as a Power BI Desktop file (pbix).

- Publish. Power BI Desktop, allows user to publish and share prepared datasets and reports to Power BI site (that is a cloud based service).

Power BI for Office 365 is a cloud based service available via web browser that allows (see [Power BI service 2016]): 
- $\quad$ Execution of similar report creation process like in Power BI desktop (import, model, create report).

- $\quad$ Connect to services. An user is able to connect to content packs for a number of services such as Salesforce, Microsoft Dynamics, and Google Analytics. Power BI uses user's credentials to connect to the service, and then creates a Power BI dashboard and a set of Power BI reports that automatically show data and provide visual insights.

- $\quad$ Create Dashboards. They are personalized and provide user capability to monitor most important data, at a glance. A dashboard combines on-premises and cloud data in a single, consolidated view across the organization.

- Sharing the data. In Power BI an user can share dashboards, reports, and tiles in several different ways eg. Publish a report to the web, share a dashboard with associates, create a dashboard in a group, then share it with coworkers outside the group.

- Q\&A in Power BI. Capability of processing natural language user's question and receive answers in the form of charts and graphs.

- Quick Insights. Power BI searches different subsets of dataset while applying a set of algorithms to discover potentially-interesting insights. Power BI scans as much of a dataset as possible in an allotted amount of time. Example algorithms are: Majority, Category outliers, Overall trends in time series, Correlation and many more.

Example Power BI dashboard is presented on the Figure 6, where solving of real problem can be illustrated in many ways.

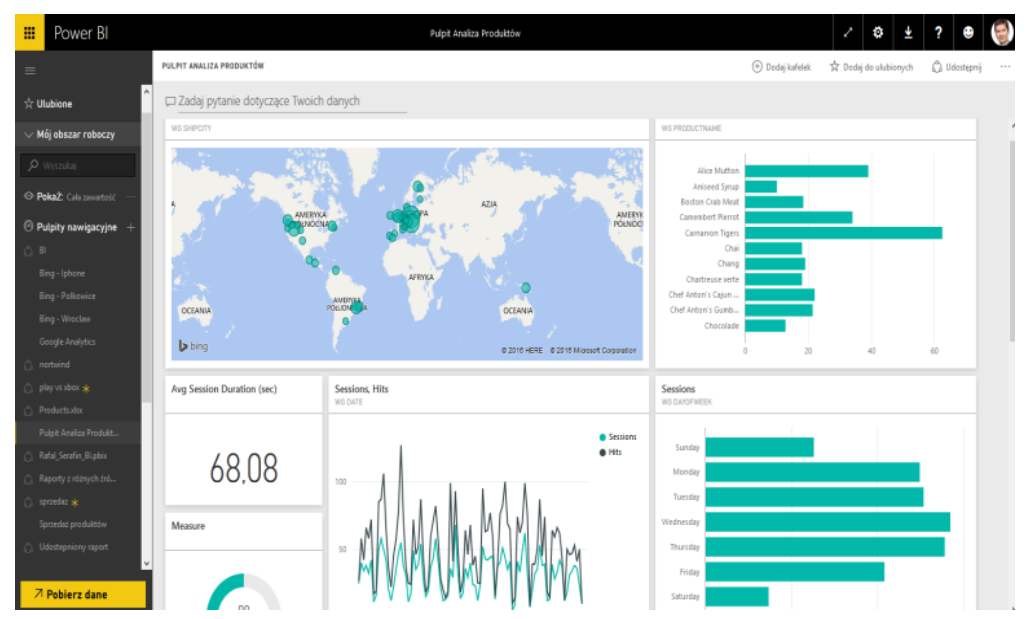

Figure 6. Power BI example dashboard Source: own work on https://app.powerbi.com 
The presented dashboard is the final result of all phases included to BI process; students can select appropriate data, perform analysis employing appointed algorithms and visualize survey outcomes using different charts.

\section{Conclusions}

The general findings of the research can be formulated as follows:

- Innovation of teaching methods relies on application of sophisticated software tools supporting all phase of BI process,

- There are plenty platforms that can be used in teaching of Business Intelligence. Quite promising capabilities are offered as free software thus these tools are real competitors for commercial products,

- For better selection of the appropriate platform the list of criteria should be elaborated. Existing rankings are very useful in formulation of the set of capabilities essential for individual users,

- The presented method of the selection platforms for teaching Business Intelligence can be applied in teaching courses devoted to advanced technologies supporting business,

Our further research can be devoted to prepare multidimensional knowledge base supporting the selection procedure.

\section{REFERENCES}

[BISP 2016] Business Intelligence software products http://www.bitool.net

[BITSe 2016] Business Intelligence Tools Selection http://www.bi-dw.info/bidw56.html

[BITSu 2016] Business Intelligence Tools Survey http://www.businessintelligencetoolbox.com

[BIV 2016] Business Intelligence Verdict http://www.bi-verdict.com/

[BP4BI 2006] Best Practices for Business Intelligence Tool Selection. http://www.b-eyenetwork.com/view/2578

[Cupoli et al., 2013] Cupoli P., Devlin B., Ng R., Petschulat S. ACM Tech Pack on Business Intelligence/Data Management. ACM 2013

[GartnerBI 2016] Gartner: Magic Quadrant for Business Intelligence and Analytics Platforms https://www.gartner.com/doc/reprints?id=1-2XXET8P\&ct=160204

[Haroun 2017] http://www.bchmsg.yolasite.com/methods.php

[Jaspersoft BI] (http: www.jaspersoft.com/)

[Laurent, A.M, 2004] Laurent, Andrew M. St. Understanding open source and free software licensing. " O'Reilly Media, Inc.", 2004.

[Martinez M.(2017)]: Gartner Positions Microsoft as a leader in BI and Analytics Platforms for ten consecutive years. https://powerbi.microsoft.com/en-us/blog/gartner-positions-microsoft-as-aleader-in-bi-and-analytics-platforms-for-ten-consecutive-years/

[MS Power BI 2016] (https://powerbi.microsoft.com/en-us/)

[Passioned Group 2017]: Business Intelligence Tools Survey 2017.

https://www.passionned.com/kb/business-intelligence-tools-survey/

[Pentaho 2016] (http: www.pentaho.com/) 
[Pondel 2015] Pondel, M.. "A concept of enterprise Big Data and BI workflow driven platform." Computer Science and Information Systems (FedCSIS), 2015 Federated Conference on. IEEE, 2015.

[PowerBI Desktop 2016] https://powerbi.microsoft.com/en-us/documentation/powerbi-desktop-getthe-desktop/

[Power BI service 2016] https://powerbi.microsoft.com/en-us/documentation/powerbi-servicebasic-concepts/

[Qlik Sense 2016] (http://www.qlik.com/products/qlik-sense)

[Quora 21] Blog on challenges of higher education. https://www.quora.com/What-are-thechallenges-for-higher-education-in-the-21st-century

[Robertson 2010] Robertson S.L.: Challenges Facing Universities in a Globalising World. https://susanleerobertson.files.wordpress.com/2012/07/2010-robertson-challenges.pdf

[SAP Lumira 2016] ( http://saplumira.com/)

[Sherman R. 2015]: How to evaluate and select the right BI tool. http://searchbusinessanalytics.techtarget.com/feature/How-to-evaluate-and-select-the-right-BIanalytics-tool

[Tableau 2016] (http: www.tableau.com/)

[Underwood 2017] http://www.jenunderwood.com/2017/02/22/2017-gartner-bi-magic-quadrantresults/

[Webb 2014] Webb, C. Power Query for Power BI and Excel. Apress, 2014

[Wikipedia/teaching_method] https://en.wikipedia.org/wiki/Teaching_method

[Wise 2012] Wise, Lindsay. Using Open Source Platforms for Business Intelligence. Avoid Pitfalls and Maximize ROI. Morgan Kaufman, 2012 